\title{
Adult Epistaxis, Epidemiology and Management at the University Hospital of The West Indies \\ R Forde $^{1}$, R Cargill ${ }^{1}$, A Batchelor ${ }^{1}$, EW Williams ${ }^{2}$
}

\begin{abstract}
Introduction: Epistaxis is one of the most common otolaryngology emergencies. There is no published data in the West Indian literature regarding its management. This study was conducted to describe the clinical characteristics and treatment outcomes of patients admitted to the University Hospital of the West Indies (UHWI) with epistaxis and to determine the prevalence of hypertension in patients presenting with epistaxis.

Methods: A retrospective chart review was performed on 40 patients admitted to the Ear, nose and throat ward through the Accident and Emergency (A\&E) Department at the UHWI between February 2007 and February 2014 with a diagnosis of epistaxis. The data were analysed using SPSS statistics 22 software.

Results: There were 40 patients with a diagnosis of epistaxis admitted to the ear, nose and throat ward. There were 22 males and 18 females. The mean age was 52.5 years (standard deviation [SD], 17.8). The prevalence of hypertension among patients with epistaxis was $72.5 \%$. The commonest cause of epistaxis was idiopathic accounting for $72.5 \%$, followed by nasal masses $10 \%$ and trauma and aspirin each $5 \%$. Anterior nasal bleeding accounted for $52.5 \%$ of cases. Ninety-five per cent of patients were managed initially with nasal packing. Surgical measures were carried out in $18 \%$ of patients who had initially been packed $(\mathrm{p}=0.046)$. The overall mean hospital stay was six (6.75) days. There was no mortality in this series.

Conclusions: The majority of nose bleeds in this review were anterior. Idiopathic remains the leading cause. Most cases of epistaxis can be managed successfully with non-surgical treatment. There is a high prevalence of elevated blood pressure readings and hypertension among this group of patients with epistaxis.
\end{abstract}

Keywords: Anterior nose bleed, epistaxis, nasal packing, posterior nose bleed

\section{La Epistaxis en Adultos, su Epidemiología y Tratamiento en el Hospital Universitario de West Indies}

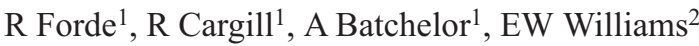

\begin{abstract}
RESUMEN
Introducción: La epistaxis es una de las emergencias más comunes de la otorrinolaringología. No hay datos publicados en la literatura de West Indies con respecto a su manejo. Se realizó este estudio para describir las características clínicas y los resultados del tratamiento a pacientes ingresados en el Hospital Universitario de West Indies (HUWI) con epistaxis, y determinar la prevalencia de la hipertensión en pacientes que acuden con epistaxis.

Métodos: Se realizó una revisión retrospectiva de los expedientes clínicos de 40 pacientes ingresados a la Sala de Garganta, Nariz y Oído a través del Departamento de Accidentes y Emergencias (A\&E) del HUWI entre febrero de 2007 y febrero de 2014, con un diagnóstico de epistaxis. Los datos fueron analizados utilizando el software de estadísticas SPSS 22.

Resultados: Hubo un ingreso de 40 pacientes con diagnóstico de epistaxis en la Sala de Garganta, Nariz y Oído. Hubo 22 hombres y 18 mujeres. La edad promedio fue 52.5 años (desviación estándar [SD],

17.8). La prevalencia de hipertensión entre los pacientes con epistaxis fue de $72.5 \%$. La causa más fre-
\end{abstract}

From: ${ }^{1}$ Department of Surgery, Radiology, Anaesthesia and Intensive Care and ${ }^{2}$ Emergency Medicine Division, Faculty of Medical Sciences, The University of the West Indies, Mona, Jamaica, West Indies.
Correspondence: Dr R Forde, Department of Surgery, Radiology, Anaesthesia and Intensive Care, The University of the West Indies, Mona, Jamaica, West Indies.

Email:royantonioforde@hotmail.com,draforde@gmail.com 
cuente de epistaxis fue idiopática, representando un $72.5 \%$, seguida por las masas nasales de un 10\%, y trauma y aspirina cada una de un 5\%. La hemorragia nasal anterior representó el 52.5\% de los casos. El noventa y cinco por ciento de los pacientes fueron tratados inicialmente con taponamiento nasal. Se llevaron a cabo medidas quirúrgicas en $18 \%$ de los pacientes que inicialmente habian sido taponeados $(\mathrm{p}=0.046)$. La media general de estancia hospitalaria fue seis días (6.75). No hubo mortalidad en esta serie.

Conclusiones: La mayoría de los sangramientos nasales en esta revisión fueron hemorragias nasales anteriores. La causa principal fue idiopática. La mayoría de los casos de epistaxis pueden ser manejados con éxito con el tratamiento no quirúrgico. Existe una alta prevalencia de lecturas de presión arterial elevada e hipertensión entre este grupo de pacientes con epistaxis.

Palabras claves: Sangrado nasal anterior, epistaxis, taponamiento nasal, sangrado nasal posterior

West Indian Med J 2017; 66 (1): 101

\section{INTRODUCTION}

Epistaxis is defined from the Greek word epistazein which means to flow, drop by drop. In 1764, Vogel suggested that this term be used to denote only nasal bleeding (1). It accounts for $0.46 \%$ of all United States of America Emergency Department visits (2). Sixty per cent of the population will have epistaxis and medical intervention will be required in $6 \%$ of cases (3). Eighty per cent of cases arise anteriorly in relation to the maxillary sinus ostium and is easily controlled by cautery and anterior nasal packing (3). It can be major or minor. Minor epistaxis usually originates from the anterior nasal septum secondary to trauma. In children, trauma is as a result of nose picking and in adults it is secondary to desiccation of the superficial small vessels in the mucosa as a result of dry air flow. Minor epistaxis may be anterior or posterior in origin. This type of epistaxis is controlled by conservative measures such as direct pressure (pinching the nose, nasal packing) and surgical intervention is rarely necessary.

Major epistaxis which is not precisely defined is a nose bleed that is difficult for patients to control. It frequently results in hospital admission and may also require blood transfusions and may be life-threatening. Most cases of major epistaxis is idiopathic, but a careful history may reveal other risk factors such as anticoagulant medications or hypertension. The prevalence rates of hypertension among patients with epistaxis is 17 to $67 \%$ (4). Whether there is an association or cause and effect relationship between epistaxis and hypertension is a subject of long standing controversy (4). Most cases of major epistaxis are posterior nose bleeds arising posterior to the maxillary sinus ostium and from branches of the sphenopalatine artery. Bleeding in these cases can therefore pose a threat to the patients' airway. Management of posterior epistaxis is controversial (5). Treatment options for epistaxis are non-surgical and surgical. There is no published data in the West Indian literature regarding the management of epistaxis in Jamaica. This study was conducted to describe the clinical characteristics and treatment outcomes of patients and to determine the prevalence of hypertension in patients presenting with epistaxis admitted to the University Hospital of The West Indies.

\section{MATERIALS AND METHODS}

The research proposal was approved by the University Hospital of the West Indies/University of the West Indies/Faculty of Medical Sciences Ethics Committee. A retrospective chart review was performed on patients who presented with internal nasal bleeding (epistaxis) to the Accident and Emergency (A\&E) Department at the UHWI between February 2007 and February 2014. The study subjects included all patients who presented through A\&E and the Ear, Nose and Throat (ENT) clinic. All the patients who presented to A\&E were admitted to the ENT ward except one. A total of 58 patients were obtained through this process. Eighteen patients were excluded because of absent charts or insufficient data logged during their admission. Data collected from their charts included age, gender, causes, type of epistaxis, duration of hospital stay, history of hypertension, blood pressure levels, haemoglobin levels and type of treatment administered.

All patients were seen by an ENT training resident after admission to the A\&E but in some cases were initially packed by the A\&E physician. Successful treatment was defined as no recurrent epistaxis following pack removal or surgery or no readmission with epistaxis within 24 hours of discharge. Hypertension in our study was defined as a mean of two blood pressure readings greater than $140 / 90 \mathrm{mmHg}$ and/or patients who present with a drug history of antihypertensive drug usage. The data were analysed using SPSS statistics 22 software to look at variables such as the mean, median, range and proportions. Further analysis was done using Pearson Chisquared analysis to determine if there was any association between hypertension and type of epistaxis, need for blood transfusion and necessity for surgical intervention. The independent samples $t$-test was used to compare the mean hospital stay between patients who were hypertensive versus those who were not hypertensive.

\section{RESULTS}

There were 40 patients with a diagnosis of epistaxis admitted to the ENT ward. There were 22 males and 18 females. Their mean age was 52.5 years (standard deviation [SD], 17.8). The median age was 56 years. The prevalence of hypertension 
among patients with epistaxis was $72.5 \%$ and the proportions of hypertensive patients in each gender were equal. The commonest cause of epistaxis was idiopathic accounting for $72.5 \%$, followed by nasal mass $10 \%$ and trauma and aspirin each $5 \%$ (Table 1 ).

Table 1: Aetiological factors; total numbers and percentages

\begin{tabular}{lcc}
\hline Aetiological Factors & Number of patients & Percentage \\
\hline Idiopathic & 29 & 72.5 \\
Nasal mass & 4 & 10 \\
Trauma & 2 & 5 \\
Multiple myeloma & 1 & 2.5 \\
Internal carotid artery aneurysm & 1 & 2.5 \\
Dilated nasal blood vessel & 1 & 2.5 \\
Aspirin & 2 & 5 \\
\hline
\end{tabular}

Anterior nasal bleeding accounted for $52.5 \%$ of cases, posterior bleeding $20 \%$ and a site not known in $27.5 \%$. Ninety-five per cent of patients were managed initially with nasal packing and $5 \%$ of patients were managed with observation alone. Fifteen patients had anterior packing and 20 patients had been packed with both anterior and posterior packs. Anterior nasal packing was successful initially in $87 \%$ but $13 \%$ required both anterior and posterior nasal packing. Eighty-two per cent of patients who had been initially packed with both anterior and posterior packs had successful treatment with this modality, but $18 \%$ or three patients required surgical intervention with either nasal cautery and/or artery ligation $[p=0.046]$ (Table 2).

Table 2: Treatment modalities, success rates and average hospital stay

\begin{tabular}{lccc}
\hline Treatment modality & $\begin{array}{c}\text { Number of } \\
\text { patients }\end{array}$ & $\begin{array}{c}\text { Success } \\
\text { rate (\%) }\end{array}$ & $\begin{array}{c}\text { Average hospital } \\
\text { stay(days) }\end{array}$ \\
\hline Observation & 5 & 100 & 3 \\
Anterior nasal packing & 15 & 87 & 4 \\
$\begin{array}{l}\text { Anterior and posterior nasal } \\
\text { packing (Posterior Packing) }\end{array}$ & 20 & 82 & 7 \\
\hline
\end{tabular}

The overall mean hospital stay was six (6.72) days (range 1 to 33 days). Embolization was not performed. There were no deaths. There was no association between hypertension and type of nose bleed. Patients who were hypertensive had a mean (SD) hospital stay of 5.6 (6.64) days versus a mean (SD) stay of 6.9 (7.2) days for those patients who were not hypertensive. There was no statistical difference in the average duration of hospital stay between the two groups $(95 \% \mathrm{CI}$, $-6.12-3.61 ; p=0.6)$. Patients who were hypertensive were less likely to receive a blood transfusion $(p=0.018)$ and were less likely to require surgical intervention $(p=0.1)$. Five per cent of patients overall required a blood transfusion. Patients who received a posterior pack had a mean (SD) stay of 7.7 (8.48) days as compared to four (2.6) days for those who required an an-terior pack [ $95 \%$ CI, $-7.52 ; 0.47 ; p=0.08]$ (Table 2).

\section{DISCUSSION}

The severity of epistaxis depends on frequency, intensity, duration, need for transfusion, presence of anaemia and aggressiveness of treatment required (6). From these parameters, a severity score may be derived. A severity score was not used in our study due to the retrospective data collection. In our study, severe or major epistaxis was defined as a nose bleed which is difficult to control and requires hospital admission. We found that $99 \%$ of our patients who presented to the A\&E Department for uncontrolled epistaxis required admission and so all 40 patients in our study were diagnosed as having major or severe epistaxis. This is compared to other studies where only $6 \%$ of patients who present to the A\&E Department are hospitalized (7).

In our culture and population, most patients would prefer to stay at home and wait for the nose bleed to resolve rather than visit an emergency room where the perception is one of long waiting times. So that most patients who visit the A\&E will be those patients where the epistaxis will be uncontrolled and severe and hence our higher rate of hospitalization.

Epistaxis tends to occur in a bimodal age related fashion with peaks in those under 10 years and those greater than 50 years (7). The majority of cases of paediatric epistaxis are treated as outpatients with rehydration of the nasal mucosa (8). For cases which are hospitalized, the average age has been quoted ranging from 47 years (9) to 60 years (10). In another study the average age was 55 years (11). The average in our study was 52.5 years which falls in between the range in averages. This age group is the second peak of presentation which is related to underlying chronic illnesses affecting the vasculature which makes initial haemostasis more difficult. The cause of epistaxis in younger patients tend to be secondary to trauma of normal vessels (8) making the initial haemostatic events more successful; hence these patients are not admitted to hospital and are managed on an outpatient basis (8).

Whether there is an association or cause and effect relationship between epistaxis and hypertension is a subject of long standing controversy (4). The prevalence of hypertension among patients with epistaxis has been quoted as low as $14 \%$ (12) to as high as $45 \%$ (4) in other studies. Our study demonstrated a high prevalence of $72.5 \%$ of patients with epistaxis who were hypertensive. Hypertension in our study was defined as a mean of two blood pressure readings greater than $140 / 90 \mathrm{mmHg}$ and or patients who present with a drug history of antihypertensive drug-usage. A retrospective cohort study comparing patients with active nose bleeds versus patients without any nose bleeds found that on average that patients with active epistaxis had a higher blood pressure at presentation than controls (systolic blood pressure $165 v 153 \mathrm{mmHg}$, $p<0.001$, diastolic blood pressure $85 v 77 \mathrm{mmHg}, p<0.001$ ) and found that active epistaxis was associated with arterial hypertension (13). Our diagnosis of hypertension was not according to the World Health Organisation (WHO) guidelines (14) but included patients presenting for the first time with an 
average of two readings. These patients might not have been true hypertensives according to the WHO guidelines but may have presented with elevated blood pressures as part of a systemic stress response. This would explain the higher prevalence of hypertension in patients presenting with epistaxis in our study when compared to other studies where hypertension was defined according to the WHO guidelines. Also a population based study found the prevalence of hypertension to be $16 \%$ in West Africa including Nigeria, 26\% in the Caribbean including Jamaica and 33\% in the United States of America (15). This would explain the higher association of hypertension that we obtained in our study compared to the $45 \%$ quoted in the Nigerian study.

We concluded that there is a high prevalence of elevated blood pressure readings and hypertension seen in our patients presenting with epistaxis. The link between hypertension and epistaxis as proposed by Shaheen is related to the fact that hypertension leads to arterial muscle degeneration which leads to a defective muscle layer which looses the power to contract once the vessel is traumatised and this leads to persistent bleeding (16).

Shaheen found structural abnormalities in the nasal vessels similar to those in the cerebral circulation of post mortem hypertensive patients (14). Another study did not find any association between blood pressure and a history of adult epistaxis in hypertensive patients and contradicted the idea that hypertension is a cause of epistaxis in hypertensive patients (14). We believe that hypertension is not the cause of epistaxis. However, elevated blood pressures may result in persistent bleeding. In our study, we found no statistical difference between the mean hospital stay between patients who were hypertensive and those who were not $(95 \% \mathrm{CI},-6.12$ $3.61 ; p=0.6)$. We postulate that during their admission, the hypertensive patients' blood pressures might have been lowered enough to a point where haemostasis would occur. Epistaxis incidence in hypertensive patients has not been found to be associated with hypertensive severity, however (11).

The aetiology of epistaxis is typically idiopathic, but it may also result from neoplasms, trauma, medication use or iatrogenic causes (17). In our study, idiopathic causes accounted for $72.5 \%$ which correlates with the worldwide literature. The hypothesis as to the cause of idiopathic has been proposed to be staphylococcus nasal colonization leading to inflammation, crusting and new vessel formation and ending with epistaxis (18). They found staphylococcus colonization to be $37 \%$ in the epistaxis group versus $19 \%$ in the control group but no difference in the prevalence of staphylococcus aureus between crust and non-crust groups (18). Another group found that apoptoses of nasal microvessels as evidenced by caspase 3 activation was a possible mechanism of the onset of epistaxis (19). Padgham found enlarged blood vessels in the nasal mucosa as the source of bleeding in $81.4 \%$ of patients who presented with epistaxis (14).

In patients admitted with epistaxis according to the bleeding site, $60 \%$ will have an anterior bleed and $25.45 \%$ a posterior bleed (9). We obtained similar results in our study. The smaller proportion of anterior epistaxis seen in inpatients is because most cases of anterior will resolve with direct pressure so we would expect a higher portion of bleeds being posterior in origin where the blood vessels are not controlled with home remedies such as pinching of the nose. Posterior epistaxis clinically is defined as active haemorrhage into the posterior pharynx without identifiable anterior bleeding or severe nasal haemorrhage refractory to anterior packing (20). It is possible that the $27.5 \%$ of patients in our study where the bleeding site was unknown might be due to a posterior bleeding site.

The emergency management of epistaxis include the use of local pressure, chemical or electric cautery, haemostatic agents, nasal packing, embolization and surgical arterial ligation. There is no definitive protocol for the management of epistaxis in our institution, although various protocols have been proposed in the literature (17). Initial management of anterior epistaxis with chemical cautery has a higher success rate and a lower number of total required interventions than nondissolvable packing. In patients who failed initially with packing, progression to cautery or proximal vascular control led to significantly shorter inpatient stays than did packing alone (2). In our setting, $95 \%$ of our patients are packed initially in A\&E. We need to develop a protocol where if the patient is not bleeding profusely or is unstable, the ENT resident should see these patients with a view to perform endoscopy and chemical cautery. This would lead to a reduction in hospital stay and cost. Bilateral nasal packing should be utilized because it causes a reduction to the nasal septal deformity and therefore creates a safer and more pleasant patient experience (21).

Management of posterior epistaxis is controversial because of the many treatment options available. These options vary in efficacy, rates of complications and cost. Posterior nasal packing is the medical management most frequently used to control posterior epistaxis. It is associated with major complications, including stroke, myocardial infarction, arrhythmias and death (5). Nasal packing is associated with lower hospital charges and similar complication rates as arterial ligation or embolization (22). A retrospective chart review suggests that a better success rate, a comparable complication rate and a cost savings can be achieved with surgical intervention as the first-line treatment for intractable epistaxis when compared with traditional anterior-posterior packing and embolization (23). Our mean hospital stay of patients who had a posterior pack was seven days. It would be interesting in our setting with the decrease in available operating time and limited resources to determine in a prospective study whether patients with early surgical intervention would have a shorter hospital stay than those who receive posterior nasal packing. Ninetyfive per cent of our patients overall were initially treated with nasal packing with a success rate of $82 \%$.

Five per cent of patients will require a general anaesthesic because of intractable epistaxis (10). In our study, $18 \%$ required surgical intervention. In our setting, the initial pack- 
ing is done by the A\&E officer which at times might not be adequate and so may explain our higher prevalence of surgical intervention compared to other studies. Our average hospital stay of six days is comparable to other studies quoting an average of six days (9). In our study, one patient stayed 22 days, another stayed 26 and another 33 days which would have skewed our average to six days.

One of the limitations of our study was the small sample size. Future prospective studies are needed to determine the association between hypertension and epistaxis. This should be at minimum a cross-sectional study of a large sample size of adult patients in our population over the age of 18 years and to determine the prevalence of epistaxis and hypertension as defined by the WHO guidelines and then to compare the two groups to see whether there is indeed a statistical significant association.

\section{CONCLUSIONS}

The majority of nose bleeds are anterior. Idiopathic remains the leading cause. Most cases of epistaxis can be managed successfully with non-surgical treatment which should include chemical cautery in cases of anterior epistaxis and nasal packing for posterior sites or where the site is unknown. There is a high prevalence of elevated blood pressure readings and hypertension among our patients with epistaxis. The average hospital stay is six days. Patients who were hypertensive had an average longer duration of hospital stay but were less likely to have received a blood transfusion or require surgical intervention. Further prospective studies are warranted to more accurately determine these trends in our population.

\section{AUTHORS' NOTE}

Roy Forde, writing the manuscript and design of study; Rodd Cargill, collection of data and design of study; Astrid Batchelor, collection of data; Eric Williams, review of manuscript. The authors declare no conflict of interests.

\section{REFERENCES}

1. Hicks JN. Cryotherapy for severe posterior nasal epistaxis: clinical and experimental study. Laryngoscope 1971; 81: 1881-902.

2. Shargorodsky J, Bleier BS, Holbrook EH, Cohen JM, Busaba N, Metson $\mathrm{R}$ et al. Outcomes analysis in epistaxis management: development of a therapeutic algorithm. Otolaryngol Head Neck Surg 2013; 149: 390-8.

3. Strong E, Bell D, Johnson L, Jacobs J. Intractable epistaxis: transantral ligation vs. embolization: efficacy review and cost analysis. Otolaryngol Head Neck Surg 1995; 113: 674-8.
4. Isezuo S, Segun-Busari S, Ezunu E, Yakubu A, Iseh K, Legbo J et al. Relationship between epistaxis and hypertension: a study of patients seen in the emergency units of two tertiary health institutions in Nigeria [Internet]. Nigerian J Clinical Practice. Medical and Dental Consultants' Association of Nigeria (MDCAN); 2009

5. Monte ED, Belmont MJ, Wax MK. Management paradigms for posterior epistaxis: A comparison of costs and complications. Otolaryngol Head Neck Surg 1999; 121: 103-6.

6. Hoag JB, Terry P, Mitchell S, Reh D, Merlo CA. An epistaxis severity score for hereditary hemorrhagic telangiectasia. Laryngoscope 2010; 120: 838-43.

7. Pallin DJ, Chng Y-M, McKay MP, Emond JA, Pelletier AJ, Camargo CA. Epidemiology of epistaxis in US emergency departments, 1992 to 2001. Ann Emerg Med 2005; 46: 77-81.

8. Damrose JF, Maddalozzo J. Pediatric epistaxis. Laryngoscope 2006; 116: 387-93.

9. Chaiyasate S, Roongrotwattanasiri K, Fooanan S, Sumitsawan Y. Epistaxis in Chiang Mai University Hospital. J Med Assoc Thai 2005; 88: 1282-6.

10. Dphil JW, Hons SF. Epistaxis : a national survey. 1996; 444-6.

11. Knopfholz J, Lima-Junior E, Précoma-Neto D, Faria-Neto JR. Association between epistaxis and hypertension: a one year follow-up after an index episode of nose bleeding in hypertensive patients. Int $\mathrm{J}$ Cardiol 2009; 134: e107-9.

12. Fuchs FD, Moreira LB, Pires CP, Torres FS, Furtado MV, Moraes RS et al. Absence of association between hypertension and epistaxis: a population-based study. Informa UK Ltd UK; 2009 Jul 8.

13. Herkner H, Havel C, Müllner M, Gamper G, Bur A, Temmel AF et al. Active epistaxis at ED presentation is associated with arterial hypertension. Am J Emerg Med 2002; 20: 92-5.

14. Neto JFL, Fuchs FD, Facco SR, Gus M, Fasolo L, Mafessoni R et al. Is epistaxis evidence of end-organ damage in patients with hypertension? Laryngoscope 1999; 109: 1111-5.

15. Cooper R, Rotimi C, Ataman S, McGee D, Osotimehin B, Kadiri S et al. The prevalence of hypertension in seven populations of west African origin. Am J Public Health 1997; 87: 160-8.

16. Razdan U, Rai Zada RM, Chaturvedi VN. Epistaxis study of aetiology, site and side of bleeding. Indian J Med Sci 1999; 53: 545-52.

17. Cooper SE, Ramakrishnan VR. Direct cauterization of the nasal septal artery for epistaxis. Laryngoscope 2012; 122: 738-40.

18. Ulusoy $\mathrm{S}$, Babaoglu $\mathrm{G}$, Cingi $\mathrm{C}$. Is there a relationship between epistaxis and Staphylococcus aureus colonization in the nasal vestibule? Otolaryngol Head Neck Surg 2013; 149 (2 Suppl): P261-P261.

19. Nakada H. Caspase 3 activation in nasal capillary in patients with epistaxis. Otolaryngol Head Neck Surg 2003; 128: 632-9.

20. Viducich RA, Blanda MP, Gerson LW. Posterior epistaxis: clinical features and acute complications. Ann Emerg Med 1995; 25: 592-6.

21. Hollis S, Titoria P. A Study into the Benefits of Bilateral Packing for Epistaxis. Otolaryngol - Head Neck Surg 2011; 145 (2 Suppl): P145P145.

22. Goddard JC, Reiter ER. Inpatient management of epistaxis: outcomes and cost. Otolaryngol Head Neck Surg 2005; 132: 707-12.

23. Klotz DA, Winkle MR, Richmon J, Hengerer AS. Surgical management of posterior epistaxis: a changing paradigm. Laryngoscope 2002; 112: $1577-82$. 